\title{
Commentary to the "Researching management in Central and Eastern Europe: researcher, manager and management practice".
}

\author{
Olga A. Strakhova / Denis Y. Frolov, St.-Petersburg University of Economics \\ and Finance
}

The article "Researching management in Central and Eastern Europe: researcher, manager and management practice" appeared in the right time. It considers the whole range of problems related to modern management practice in Eastern Europe. The problems are also relevant to the situation in Russia, theoretical and practical issues.

In our opinion, the author of the article successfully formulated one of the important problems of the management in the transforming and emerging economic systems - development of the participative approach and its influence on the practice management. There are no doubts that the implementation of the approach in Russia would be very effective and useful in the changing environment. The approach was always used by the commercial companies whose services in great extent were based partly on the management information and feedback (business consulting, audit etc.). Purposes of the scientific researches are obviously different from the aims of the commercial firms. But still the methods, which are used to stimulate managers' co-operation, can be the same: increase in the efficiency of the researched enterprises. The most simple example of the mutually beneficial co-operation is testing of internal controls: researcher gets study material, experience, base for further work and models of management and the top management receives information on the possible weakness of certain parts of control systems ('bottle necks', unsuitable segregation of duties, probability of frauds or misstatements etc.).

We should although mention here that one of the most important issues at this stage is to work and communicate with the middle level management and personnel. It is extremely important especially in the countries where personal relationships have significant influence on the provided information and feedback (Russia, Spain etc.)

In Russia, unfortunately, the necessary scientific researches do not receive appropriate financing resources, on one hand, and, on the other hand, top management of the most Russian enterprises is very rare ready to investigate and discuss problems with the researches. The two issues significantly slow down the processes of the 'participative' approach implementation.

Nowadays, in Russia, during management research conducting, it is very important to communicate with managers based on the assessments of their personal professional development level. It is true that until now many regional managers in Russia still continue to practice survival management. There are different reasons for that: internal, i.e. difficulties within their organisations (ineffective structures of the organisations, inappropriate personnel, manual non- 
computerised accounting etc.); external, i.e. changing environment (lack of financing resources, unstable legislation and tax system, social tension, low efficiency etc.). Lack of managerial education also forces them to apply the most simple but inefficient management methodologies.

It is obvious that the old type of manager, - the manager of the administrative socialist system, - is unacceptable for the new market economy. Russian managers were more oriented to the obedience rather than to the taking of responsibility. They were not interested in the personal professional development, because for career purposes it was more important to get close relationships with the direct seniors and useful contacts with the 'right' people.

The situation changed and now the economy demands new type of manager. He has to understand of the modern market relationships, he has to possess certain knowledge of the management culture and education. The new manager needs to have strategic mentality, he has to be able to accept new ideas. It means that the new business leader must be agree to study and he must understand necessity of his own professional development. This is the first and the most important change in the practice management, which should be applied in Russian enterprises. Solution of the other internal management problems depends only on the level of managers' development and their ability for development.

This issue also involves changes in the work with management personnel (assessment of the personnel, choice, incentives, training etc.). All the necessary changes imply extension of the international co-operation, development of the management culture of the whole society.

Conclusions of the article "Researching management" relate to the necessity of the mutual researches in practice management, to the spreading results and examples of successful management practice. These are quite relevant for Russian enterprises and certainly should be implemented in both researches and practice management. Exchange of the experience can be also performed during international conferences. 